\title{
Microporous Polysaccharide Hemospheres and Seroma Formation After Mastectomy and Axillary Dissection in Rats
}

\author{
Tufan Egeli , Ali İbrahim Sevinç ${ }^{1}$, Seymen Bora ${ }^{1}$, Mehmet Can Yakut ${ }^{1}$, Tansu Cevizci ${ }^{1}$, Tülay Canda², Ali Rıza Şişman ${ }^{3}$ \\ ${ }^{1}$ Department of General Surgery, Faculty of Medicine, Dokuz Eylül University, İmir, Turkey \\ ${ }^{2}$ Department of Pathology, Faculty of Medicine, Dokuz Eylül University, Izmir, Turkey \\ ${ }^{3}$ Department of Biochemistry, Faculty of Medicine, Dokuz Eylül University, İmir, Turkey
}

\section{ABSTRACT}

Objective: Seroma is the most common complication after breast surgery. Several methods have been proposed to prevent seroma, but none of these provided a significant effect. A prolonged wound healing process is the most important cause of seroma. Microporous polysaccharide hemospheres $(\mathrm{MPH})$ are used to achieve hemostasis. They may also accelerate wound healing. In this study, the effects of MPH on seroma formation were investigated.

Material and Methods: Female Wistar rats weighing between $200 \mathrm{~g}$ and $250 \mathrm{~g}$ were used. There were eight rats in each of the control and study groups. Right breast mastectomy and axillary dissection were performed in all rats. While no application was performed after the operation in the control group, $\mathrm{MPH}$ was locally applied to the surgical site in the study group. Ten days after the operation, seroma fluid was aspirated and the total volume was recorded. The aspirates were analyzed and tissue samples were obtained from the surgical site.

Results: Seroma was significantly lower in the study group $(p=0.001)$. The mean albumin and lactate dehydrogenase levels were significantly lower in the study group $(p=0.003$ ). Pathological examination revealed that increase in fibrous tissue was significantly greater in the control group ( $p=0.032$ ).

Conclusion: MPH may reduce seroma after mastectomy.

Key Words: Seroma, mastectomy, microporous polysaccharide hemospheres, wound healing

\section{Introduction}

Seroma formation is the most common complication following mastectomy and axillary dissection, occurring in $10 \%-50 \%$ of cases (1-4). Since seromas usually resolve within a few weeks, seroma formation is considered as an acceptable complication by the surgeons when compared with other complications of mastectomy and axillary dissection (5). However, seromas can lead to a number of serious complications including wound infection, lymphedema, flap necrosis, prolonged length of hospital stay, sepsis, as well as delay in initiation of adjuvant therapy. Several methods have been proposed to prevent seroma formation, but none of these methods provided a significant effect $(1,6,7)$. Therefore seroma is still a serious problem and new methods are required in order to prevent it.

The pathophysiological changes underlying seroma formation remain unclear $(7,8)$. It has traditionally been assumed that drainage of lymph from divided mammary and axillary lymphatics secondary to mastectomy is responsible for seroma formation $(1,8,9)$. More recent studies have pointed out loculation of the inflammatory exudate due to prolonged wound healing $(1,6,8,10)$.
Microporous polysaccharide hemospheres (Arista ${ }^{T M} A H \circledast$, Medafor Inc., Minneapolis, MN, United States of America) are in the form of powder, plant-based, and act as hydrophilic molecular sieves. MPH particles form a gelled matrix by concentrating blood solids such as platelets, red blood cells, and blood proteins such as, albumin, thrombin and fibrinogen; thus, are used to achieve hemostasis in case of persistent bleeding $(11,12)$. Also, many studies have shown that polysaccharides accelerate and enhance wound healing via various mechanisms, primarily by increasing the activity of macrophages (13-20). It can be presumed that the MPH can reduce seroma formation by virtue of these characteristics, by preventing the mechanisms causing seroma formation.

The present study was aimed to investigate the effects of $\mathrm{MPH}$ on lymphovascular drainage and delay in wound healing, which have been blamed for seroma formation.

\section{Material and Methods}

The present study was conducted in the Experimental Animal Laboratory of Dokuz Eylul University, Faculty of Medicine after obtaining approval from the Local Committee on Animal Research Ethics. Sixteen female Wistar albino rats 


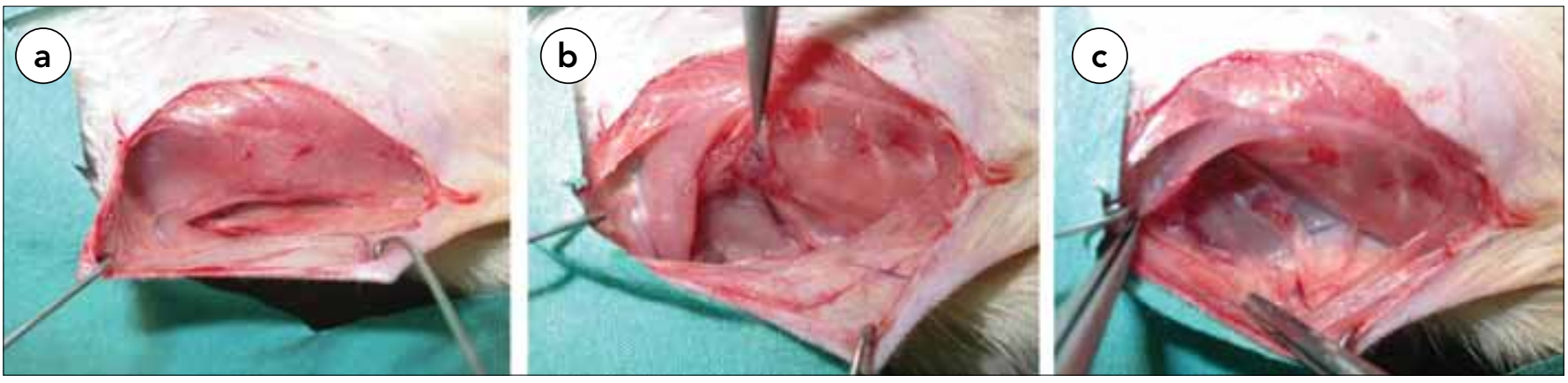

Figure 1. Surgical technique; the skin and subcutaneous tissues on the right side were decollated from the chest wall following a midline incision, extending from the suprasternal notch to the xiphoid process (a), the pectoral muscle was dissected and partially resected at the first step; the fatty cellular tissue was exposed by means of dissection (b), and the pectoral muscle was completely resected, the fatty cellular tissue in the axillary fossa was excised while preserving the axillary artery, vein and nerve (c)

weighing between $200 \mathrm{~g}$ and $250 \mathrm{~g}$ were used. All rats were fed with standard laboratory diet and tap water, and housed under controlled conditions of temperature with $12 \mathrm{~h}$ light/ dark cycle. Rats were divided into two groups, each including eight rats. No additional application was performed after the operation in the first group (control group). MPH was locally applied after the operation before the closure of the skin in the second group (study group). To achieve anaesthesia, ketamine (Ketalar $\circledast$, Parke Davis and Co. Inc., Detroit, Michigan, United States of America) was administered intraperitoneally at a dose of $50 \mathrm{mg} / \mathrm{kg}$, and xylazine (Rompun ${ }^{\circledR}$, Bayer, Leverkusen, North Rhine-Westphalia, Germany) was administered intramuscularly at a dose of $5 \mathrm{mg} / \mathrm{kg}$.

Right breast mastectomy and axillary dissection were performed in all rats in accordance with the method described by Harada et al. (21). After the surgical site was shaved, it was cleansed with $10 \%$ povidone-iodine solution for antiseptic treatment of the skin. A vertical incision was made, extending from the jugular notch to the xiphoid process. The skin and subcutaneous tissues were dissected free from the chest wall (Figure 1a). The pectoralis major muscle was dissected up to the level of the latissimus dorsi muscle, freed, and then excised (Figure 1b). All axillary lymph nodes were excised while preserving the integrity of the axillary artery, vein, and nerve (Figure 1c). After hemostatic control was established, the skin was closed with 2-0 silk suture without making any additional application in the control group and after local application of $\mathrm{MPH}$ to the surgical site in the study group.

The rats were monitored for 10 days after the operation. After 10 days, seroma fluid was aspirated from the surgical site under ketamine anaesthesia, and the total volume in milliliters was recorded. Furthermore, these aspirates were analyzed for total protein, albumin, lactate dehydrogenase (LDH), C-reactive protein (CRP) and white blood cell count. The tissue samples obtained from the surgical site were histopathologically examined. The following cytological and histopathological features were examined and graded semiquantitatively on a 0 to 3 +scale, in which $0=$ absent, $1=$ mild, $2=$ moderate, and $3=$ =marked; vascular proliferation, fibrin deposition, hemorrhage, edema, necrosis, congestion, microorganisms, polymorphonuclear leukocytes, fibroblasts, lymphocytes, macro-

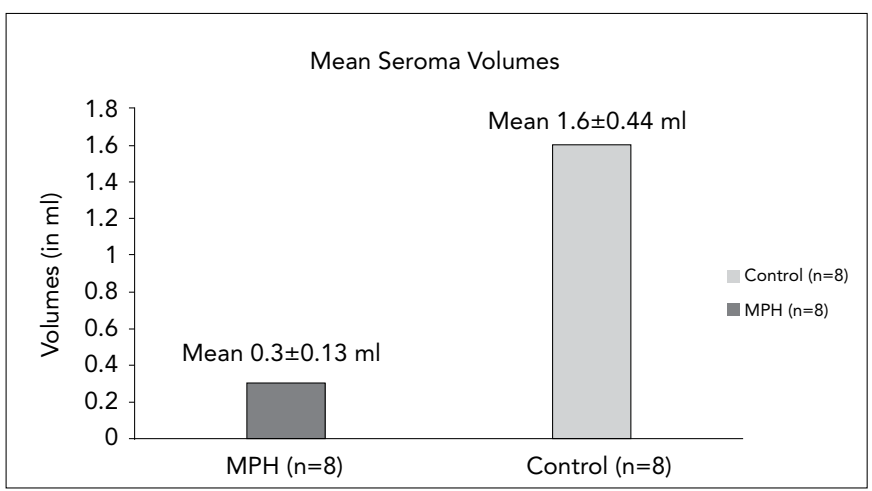

Figure 2. The mean seroma volume in the study and control groups on postoperative day 10 . Significant differences were found between control and experiment animals $(p=0.001)$

phages and increase in fibrous tissue. The rats were sacrificed after sampling.

\section{Statistical analysis}

Statistical analysis of the data was performed using Statistical Package for the Social Sciences (version 15.0; SPSS Inc., Chicago, IL, United States of America). Data regarding seroma volumes and biochemical parameters were evaluated using the Mann-Whitney $U$ test, whereas data regarding histopathological grades were evaluated using the Fisher's exact test. A $p$ value $<0.05$ was considered statistically significant.

\section{Results}

All rats were healthy during the course of the experiment. While seroma formation was observed in all rats in the control group, seroma formation was not noted in three rats in the study group. The mean seroma volume was $1.6 \mathrm{~mL}$ (standard deviation $0.44 \mathrm{~mL}$ ) and $0.3 \mathrm{~mL}$ (standard deviation $0.13 \mathrm{~mL}$ ) in the control and study groups, respectively. The mean seroma volume was significantly lower in the study group $(p=0.001)$ (Figure 2$)$.

The amount of tissue excised from three rats in the study group was not sufficient for histopathological evaluation; thereby these samples were not examined. No microorganism, edema, hemorrhage or necrosis was detected in any of 
the samples examined. No significant difference was found between the two groups in terms of vascular proliferation and congestion ( $p=1.00$ for both parameters). Macrophages and fibroblasts were more numerous in the control group as compared to the study group, however the difference was not significant ( $p=0.565$ for both parameters) (Figure 3 ). The increase in fibrous tissue was greater in the control group, and the difference was significant $(p=0.032)$.

The seroma aspirates obtained from the control and study groups were analyzed for total protein, albumin, LDH, CRP and white blood cell count. Since there was no seroma formation in three rats in the study group, only five aspirates were evaluated. The CRP levels were so low that they could not be measured in either group. The comparison of the two groups with respect to biochemical parameters revealed that the mean albumin and LDH levels, as well as the white blood cell count, were significantly higher in the control group $(p=0.03$ for all parameters) (Table 1). The mean total protein level was also higher in the control group, but the difference was not significant $(p=0.05)$.

\section{Discussion}

Although seroma formation is frequently encountered after mastectomy and axillary dissection, and also may occur after all surgical procedures that involve elevating skin flaps $(2,9)$. The need for new therapy methods for preventing seroma continues.

The pathophysiological changes underlying it are not clear $(6,7)$. The fluid collection has traditionally been attributed to drainage of lymph from divided mammary and axillary lymphatics $(1,8,9)$. However, recent studies have shown that seroma fluid composition is different from lymph, but is similar to inflammatory exudate (6). The formation of inflammatory exudate occurs due to a delay in the process of wound healing. A delay in the early inflammatory phase of the healing process leads to the uncontrolled release of exudate which is rich in inflammatory cells, structural molecules, cytokines, and growth factors under the influence of histamine and bradykinin. This uncontrolled exudation results in seroma. Seroma itself also negatively affects the healing process. In a study that compares the composition of seroma fluid with lymph and plasma, it was shown seroma fluid contained significantly greater levels of high-molecular-weight proteins, such as albumin and globulin than plasma or lymph (1). This particular result supports the view that seroma fluid shows the characteristics of inflammatory exudate.

Because inflammatory exudative liquid loculation usually developed in subjects that had breast surgery, views have been put forward for explaining why the wound healing is often pronlonged in these operations. Delay in the wound healing process following mastectomy and axillary dissection occuring due to the failure of flaps to adhere to the axilla and anterior chest wall after the operation is the most frequently accepted among these (9). In other words, it can be defined as inability of the wound edges to join together. To achieve this closure, bovine thrombin, fibrin glue, talc, tranexamic acid, Corynebacterium parvum, tetracycline and several antineoplastic agents have been used, but all these approaches have failed to provide a significant effect $(7,9)$. In 1913, Halsted described fixation of the skin flaps to the chest wall using sutures and found that this approach reduced seroma formation (22). Similarly, Aitken et al. (23) and Coveney et al. (24) also reported that the amount of seroma fluid decreased with

Table 1. Mean values of the biochemical parameters of the two groups and statistical results of their comparison

\begin{tabular}{|c|c|c|c|}
\hline Parameters & $\begin{array}{l}\text { Control group } \\
\text { (mean } \pm \text { SD) }\end{array}$ & $\begin{array}{l}\text { Study group } \\
\text { (mean } \pm \text { SD) }\end{array}$ & $\mathrm{p}$ \\
\hline Total protein $(\mathrm{g} / \mathrm{dL})$ & $1.5 \pm 0.261$ & $0.354 \pm 0.042$ & 0.05 \\
\hline Albumin (g/dL) & $1.45 \pm 0.517$ & $0.044 \pm 0.006$ & 0.03 \\
\hline $\begin{array}{l}\text { Lactate dehydrogenase } \\
(\mathrm{U} / \mathrm{L})\end{array}$ & $1778 \pm 397.1$ & $396.4 \pm 68.7$ & 0.03 \\
\hline $\begin{array}{l}\text { White blood cell count } \\
\left(\times 1000 / \mathrm{mm}^{3}\right)\end{array}$ & $9.95 \pm 1.13$ & $1.57 \pm 0.24$ & 0.03 \\
\hline
\end{tabular}

SD: standard deviation

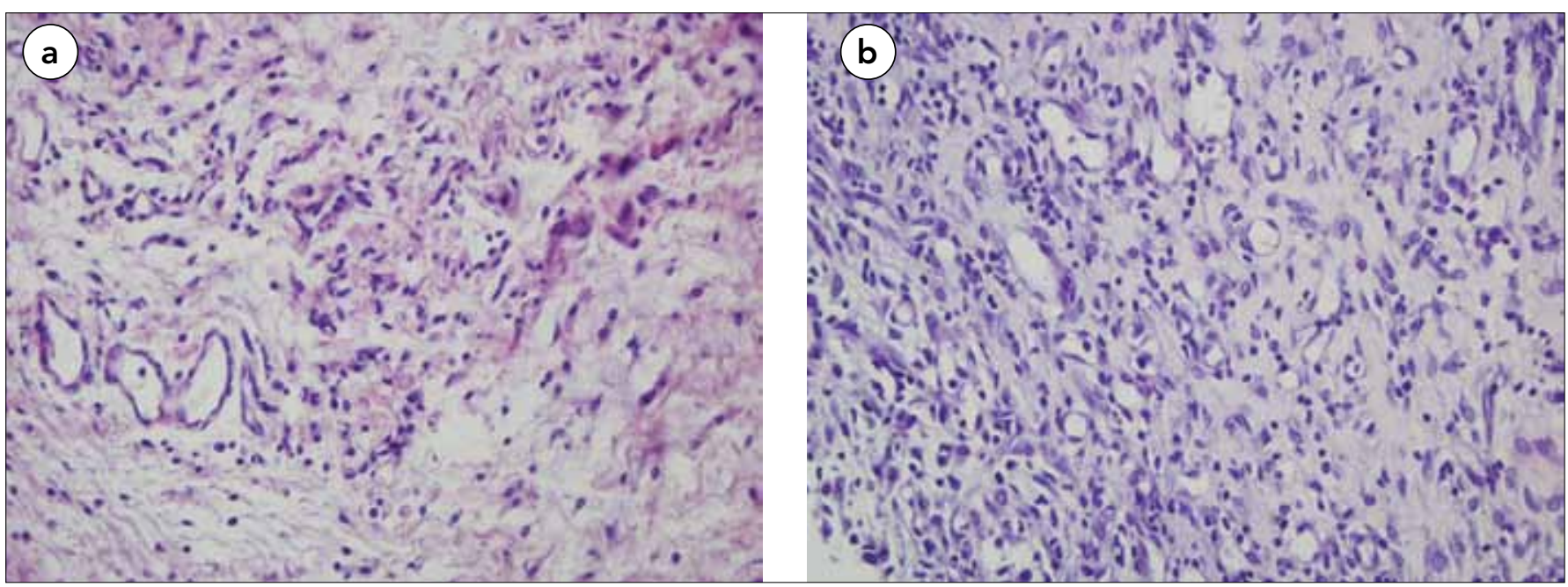

Figure 3. Two microscopic images from the study (a) and control (b) groups. Macrophages and fibroblasts are more numerous in the control group (H\&E, x 400) 
the fixation of the flaps to the anterior chest wall via deep sutures, without interrupting the circulation. However, these studies have not been satisfactory because of poor cosmetic outcomes and increased morbidity, as well as the lack of support from other studies.

$\mathrm{MPH}$ used in the present study is a hemostatic agent, the efficacy of which has been proven by a number of clinical studies. MPH is a plant-based polysaccharide in the form of powder. MPH acts as a hydrophilic molecular sieve. It forms a gelled matrix in its application area by concentrating blood solids such as platelets, red blood cells, and blood proteins such as albumin, thrombin and fibrinogen. Gelled and concentrated cells and compounds accelerate the normal clotting process by acting as a framework for immediate formation of a fibrin clot within seconds. MPH is a fully absorbable material and passes through the systemic circulation in 24-48 hours after application $(11,12)$.

Such characteristics of MPH may prevent lymphatic and vascular drainage that lead to seroma formation. Moreover, $\mathrm{MPH}$ may play a positive role in the wound healing process due to its polysaccharide structure, since MPH is a plantbased polysaccharide. Many studies have shown that polysaccharides accelerate the healing process primarily by macrophage activation (13-20) as well as by fibroblast stimulation (25-27) and by T-cell stimulation.

According to the current studies, it is understood that the most important factor in seroma formation is the delay in the wound healing process. In our study, differing from previous methods, it is aimed to accelerate the natural process of wound healing in order to eliminate this problem and it is original in that respect. For this purpose $\mathrm{MPH}$, which is expected to provide the targeted effect by its biological characteristics, is used topically in the study. It is also the first study with respect to the assessment of the effectiveness of topical application of MPH on wound healing. In addition, when compared to the other materials used in the past for this purpose, it is a cost effective agent that is easier to apply and with no potential side effect.

The results of the present study demonstrated that the amount of seroma fluid was significantly lower in the study group $(p=0.001)$. Moreover, total protein, albumin and LDH levels, and white blood cell count, which were expected to increase in a seroma, were also lower in the study group as compared to the control group. These results suggested that $\mathrm{MPH}$ applied to the study group reduced seroma formation.

Histopathological comparison of the two groups revealed that increase in fibrous tissue was significantly greater in the control group as compared to the study group $(p=0.032)$. The number of macrophages and fibroblasts were higher in the control group as compared to the study group; however, the difference did not reach statistical significance. These cells, which play an essential role in the wound healing process, gradually increase in number in the early phase of the healing process, reach their peak levels, and gradually reduce as the healing process progresses (28). On the other hand, the space between the tissues is filled with fibrous tissue during the healing process of the wound edges. The space between the two edges is directly proportional to the required amount of fibrous tissue.
Increased number of macrophages and fibroblasts in the control group as compared to the study group suggested a delayed, more slowly progressing wound healing process in the control group. Persistence of the cells such as macrophages in particular, which increase in number during the inflammatory phase, indicated an incomplete inflammatory phase in these tissues. In addition, large amounts of seroma fluid in the control group made it relatively difficult for the skin flap to adhere to the chest wall, and thus created a wider space between the tissues, causing a greater increase in fibrous tissue in the control group. Histopathological findings were interpreted as that MPH accelerated the wound healing process, and thus reduced seroma formation and its related negative effects.

There have been limitations such as not being able to use more specific indicators due to financial deficiencies in tracking the wound healing process and insufficient test subjects because only a limited number of subjects was permitted in the study. Therefore in the new studies to be conducted, more satisfying results for the researchers may be achieved by using more test subjects and more specific indicators. MPH as an agent already used in humans will enable performing of the clinical studies easier.

\section{Conflict of Interest}

No conflict of interest was declared by the authors.

\section{References}

1. McCaul JA, Aslaam A, Spooner RJ, Louden I, Cavanagh T, Purushotham AD. Aetiology of seroma formation in patients undergoing surgery for breast cancer. Breast 2000;9:144-8. [CrossRef]

2. Chung TL, Holton LH 3rd, Goldberg NH, Silverman RP. Seroma prevention using Mytilus edulis protein in a rat mastectomy model. Breast J 2006;12:442-5. [CrossRef]

3. Gonzalez EA, Saltzstein EC, Riedner CS, Nelson BK. Seroma formation following breast cancer surgery. Breast J 2003;9:385-8. [CrossRef]

4. Hashemi E, Kaviani A, Najafi M, Ebrahimi M, Hooshmand H, Montazeri A. Seroma formation after surgery for breast cancer. World J Surg Oncol 2004;9;2:44.

5. Kuroi K, Shimozuma K, Taguchi T, Imai H, Yamashiro H, Ohsumi S, et al. Evidence-based risk factors for seroma formation in breast surgery. Jpn J Clin Oncol 2006;36:197-206. [CrossRef]

6. Kuroi K, Shimozuma K, Taguchi T, Imai H, Yamashiro H, Ohsumi S, et al. Pathophysiology of seroma in breast cancer. Breast Cancer 2005;12:288-93. [CrossRef]

7. Tekin E, Kocdor MA, Saydam S, Bora S, Harmancioglu O. Seroma prevention by using Corynebacterium parvum in a rat mastectomy model. Eur Surg Res 2001;33:245-8. [CrossRef]

8. Pogson CJ, Adwani A, Ebbs SR. Seroma following breast cancer surgery. Eur J Surg Oncol 2003;29:711-7. [CrossRef]

9. Gardner A, Pass HA, Prance S. Techniques in the prevention and management of breast seroma: An evaluation of current practice. DWOR 2005;5:135-43. [CrossRef]

10. Stehbens WE. Postmastectomy serous drainage and seroma: probable pathogenesis and prevention. ANZ J Surg 2003;73:877-80. [CrossRef]

11. Murat FJ, Ereth MH, Dong Y, Piedra MP, Getman MT. Evaluation of microporous polysaccharide hemospheres as a novel hemo- 
static agent in open partial nephrectomy: favorable experimental results in the porcine model. J Urol 2004;72:1119-22. [CrossRef]

12. Tan SR, Tope WD. Effectiveness of microporous polysaccharide hemospheres for achieving hemostasis in mohs micrographic surgery. Dermatol Surg 2004;30:908-14. [CrossRef]

13. Schepetkin IA, Quinn MT. Botanical polysaccharides: macrophage immunomodulation and therapeutic potential. Int Immunopharmacol 2006;6:317-33. [CrossRef]

14. Kwon KH, Kim KI, Jun WJ, Shin DH, Cho HY, Hong BS. In vitro and in vivo effects of macrophage-stimulatory polysaccharide from leaves of Perilla frutescens var. crispa. Biol Pharm Bull 2002;25:367-71. [CrossRef]

15. Cheng A, Wan F, Wang J, Jin Z, Xu X. Macrophage immunomodulatory activity of polysaccharides isolated from Glycyrrhiza uralensis fish. Int Immunopharmacol 2008;:43-50. [CrossRef]

16. Artursson $P$, Edman $P$, Ericsson JL. Macrophage stimulation with some structurally related polysaccharides. Scand J Immunol 1987;25:245-54. [CrossRef]

17. Siripokasupkul R, Chansiripornchai P, Pramatwinai C, Rangsipipat A, Pongsamart S. The wound healing efficacy of durian polysaccharide gel (PG) dressing film in dog skin. Thai J Pharm Sci 2004;28:29.

18. Trombetta D, Puglia C, Perri D, Licata A, Pergolizzi S, Lauriano $E R$, et al. Effect of polysaccharides from Opuntia ficus-indica (L.) cladodes on the healing of dermal wounds in the rat. Phytomedicine 2006;13:352-8. [CrossRef]

19. Su CH, Sun CS, Juan SW, Hu CH, Ke WT, Sheu MT. Fungal mycelia as the source of chitin and polysaccharides and their applications as skin substitutes. Biomaterials 1997;8:1169-74. [CrossRef]
20. Chansiripornchai $P$, Pramatwinai $C$, Rungsipipat $A$, Ponsamart $S$, Nakchat $O$. The efficiency of polysaccharide gel extracted from fruit-hulls of durian (Durio zibethinus L.) for wound healing in pig skin. Acta Hort 2005;679:37-43.

21. Harada RN, Pressler VM, McNamara JJ. Fibrin glue reduces seroma formation in the rat after mastectomy. Surg Gynecol Obstet 1992;175:450-4.

22. Wei D, Zhang L, Williams DL, Browder IW. Glucan stimulates human dermal fibroblast collagen biosynthesis through a nuclear factor-1 dependent mechanism. Wound Repair Regen 2002;10:161-8. [CrossRef]

23. Wei D, Williams D, Browder W. Activation of AP-1 and SP1 correlates with wound growth factor gene expression in glucan-treated human fibroblasts. Int Immunopharmacol 2002;2:1163-72. [CrossRef]

24. Tang XM, Chegini N, Rossi MJ, Fay MF, Masterson BJ. The effect of surgical glove powder on proliferation of human skin fibroblast and monocyte/macrophage. J Gynecol Surg 1994;10:139-50. [CrossRef]

25. Broughton $G$ 2nd, Janis JE, Attinger CE. The basic science of wound healing. Plast Reconstr Surg 2006;117:12S-34S. [CrossRef]

26. Halsted WS. Developments in skin-grafting operation for cancer of the breast. JAMA 1913;60:416-8. [CrossRef]

27. Aitken DR, Hunsaker R, James AG. Prevention of seromas following mastectomy and axillary dissection. Surg Gynecol Obstet 1984;158:327-30.

28. Coveney EC, O'Dwyer PJ, Geraghty JG, O'Higgins NJ. Effect of closing dead space on seroma formation after mastectomy-a prospective randomized clinical trial. Eur J Surg Oncol 1993;19:143-6. 